\title{
Novel application of differential thermal voltammetry as an in-depth state-of-health diagnosis method for lithium-ion batteries
}

\author{
Yu Merla ${ }^{*}$, Billy Wu $W^{b}$, Vladimir Yufitc, Nigel P. Brandonc, Ricardo F. Martinez-Botas ${ }^{a}$ and Gregory J. \\ Offer ${ }^{a, c}$
}

a Department of Mechanical Engineering, Imperial College London, Exhibition Road, South Kensington Campus, London, SW7 2AZ, UK

b Dyson School of Design Engineering, Imperial College London, Exhibition Road, South Kensington Campus, London, SW7 2AZ, UK

c Department of Earth Science and Engineering, Imperial College London, Exhibition Road, South Kensington Campus, London, SW7 2AZ, UK * e-mail of corresponding author: yu.merla09@imperial.ac.uk

\section{HigHLIGHTS:}

- Accelerated ageing of lithium-ion cells under various storage/loading conditions.

- Degradation analysis was performed using various in-situ diagnosis methods.

- Differential thermal voltammetry (DTV) suitable for electric vehicle application.

- State-of-health estimation through quantitative analyses of DTV peak evolution.

\section{AUTHOR E-MAIL ADDRESS}

Yu Merla - yu.merla09@imperial.ac.uk BillyWu - billy.wu@imperial.ac.uk Vladimir Yufit - v.yufit@imperial.ac.uk Nigel P. Brandon - n.brandon@imperial.ac.uk Ricardo F. Martinez-Botas - r.botas@imperial.ac.uk Gregory J. Offer - gregory.offer@imperial.ac.uk

\section{ABSTRACT}

Understanding and tracking battery degradation mechanisms and adapting its operation have become a necessity in order to enhance battery durability. A novel use of differential thermal voltammetry (DTV) is presented as an in-situ state-of-health (SOH) estimator for lithium-ion batteries.

Accelerated ageing experiments were carried on 5Ah commercial lithium-ion polymer cells operated and stored at different temperature and loading conditions. The cells were analysed regularly with various existing in-situ diagnosis methods and the novel DTV technique to determine their $\mathrm{SOH}$. The diagnosis results were used collectively to elaborate the degradation mechanisms inside the cells. The DTV spectra were decoupled into individual peaks, which each represent particular phases in the negative and positive electrode combined. The peak parameters were used to quantitatively analyse the battery SOH. 
A different cell of the same chemistry with unknown degradation history was then analysed to explore how the cell degraded. The DTV technique was able to diagnose the cell degradation without relying on supporting results from other methods nor previous cycling data.

\section{KEYWORDS:}

- Lithium-ion battery

- Degradation

- State-of-Health

- Differential thermal voltammetry

- Stoichiometric drift

\section{ACRONYMS AND NOMENCLATURES}

$\mathrm{C}_{\text {D.L. }} \quad$ Double layer capacitance

$\mathrm{CPE}_{\mathrm{D} . \mathrm{L}}$. Double layer constant phase element

DTV Differential thermal voltammetry

ECM Equivalent circuit model

EIS Electrochemical impedance spectroscopy

HF High frequency

ICM Incremental capacity method

LAM Loss of active material

LCO Lithium cobalt oxide

LLI Loss of lithium inventory

LMO Lithium metal oxide

LTO Lithium tin oxide

MF Medium frequency

NMC Nickel manganese cobalt

NMR Nuclear magnetic resonance

OCP Open circuit potential

R Resistance

$\mathrm{R}_{\mathrm{S}} \quad$ Series resistance

SEI Solid electrolyte interphase

SOC State-of-charge

$\mathrm{SOH}$ State-of-health

SRCV Slow rate cyclic voltammetry

$t$ Time

T Temperature

Q Charge

V Voltage 


\section{INTRODUCTION}

Recent applications of lithium-ion batteries, particularly in decarbonising transport and enabling greater use of intermittent renewable energy sources on the electrical grid, are requiring lithium-ion batteries to operate under far more aggressive conditions with greater lifetime requirements.

For these applications, in addition to better cells, designers of large and complex battery systems require an improved understanding of these batteries during operation in order to diagnose problems and predict performance in real time. Developing the tools and knowledge required by these engineers is a key challenge in battery research. Predicting battery characteristics such as voltage and temperature in response to a given load within a narrow range of operating conditions, is relatively straightforward, and many models and tools exist already [1-3], but understanding, predicting and diagnosing degradation, and hence state-ofhealth $(\mathrm{SOH})$, is significantly harder [4,5]. In response to this, a large number of groups have accepted this challenge in recent years, and there has been significant progress in; understanding the dominant degradation mechanisms [6], developing pioneering techniques for diagnosis $[7,8]$, and establishing models incorporating individual degradation mechanisms [1].

Despite this progress, no unified lithium-ion battery degradation models currently exist. Without these tools it is impossible to maximise the operational life of a battery pack. It is also difficult to correctly determine the optimum operating condition for the battery pack making it prone to premature failure. Design engineers currently have to over-engineer a battery pack in order to mitigate this uncertainty which can significantly increase the cost of the product.

Similarly, the ability to take an unknown cell, and diagnose how it has degraded based upon an understanding of the fundamental degradation mechanisms has rarely been demonstrated. This is essential, as this work will demonstrate that 2 cells with identical 'capacity fade' but different histories can behave very differently in the future.

This work presents the use of various in-situ diagnostic techniques to identify the principle degradation mechanisms that have occurred in 2 lithium-ion cells that were subjected to different accelerated ageing experiments. The experiments were designed to deliberately excite certain mechanisms which are discussed in more detail below $[6,9,10]$. The cells are then diagnosed using the recently developed novel diagnostic technique, differential thermal voltammetry (DTV) [11], and the results are discussed in comparison with three other commonly used diagnostic techniques: electrochemical impedance spectroscopy (EIS), incremental capacity method (ICM), and slow-rate cyclic voltammetry (SRCV). Finally, a cell with an unknown history but the same chemistry was diagnosed using DTV and probable explanation for how the cell has degraded is presented and discussed. 


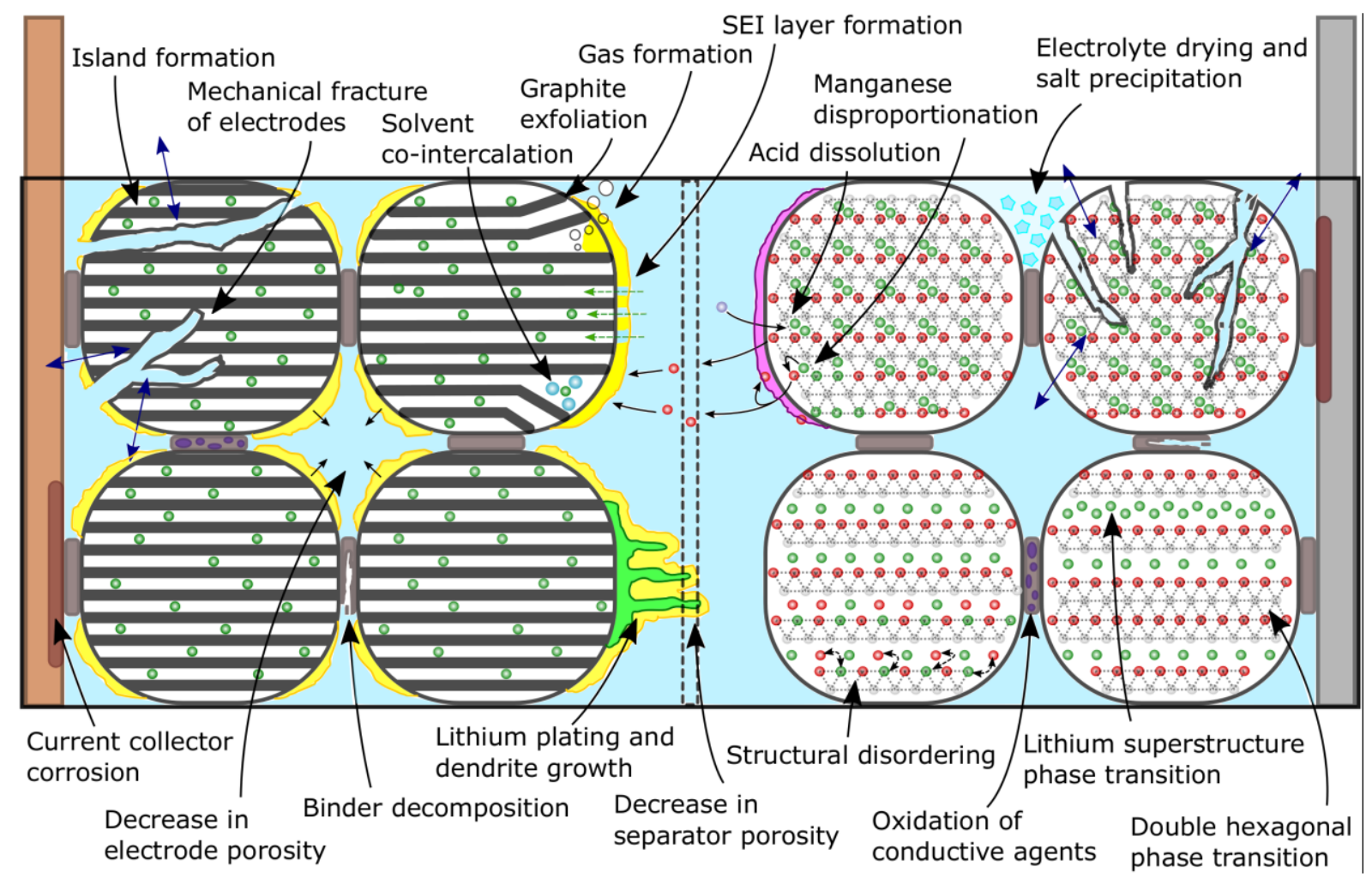

Figure 1. Schematic of key degradation mechanisms in a lithium-ion battery. Graphitic carbon negative electrode on the left. Lithium metal oxide structure on the right (upper spinel structure; lower layered structure). Separator mesh layer in the middle. Green for lithium. Red for metal. Blue for electrolyte.

\section{BACKGROUND}

The rate of degradation depends on various storage and operating conditions such as voltage, current, temperature and pressure[6,12]. These can all lead to various degradation mechanisms in different parts of the cell such as solid electrolyte interphase (SEI) layer formation at the negative electrode or metal dissolution at the positive electrode. Figure 1 illustrates the most important degradation mechanisms identified here for lithium-ion batteries with a graphitic carbon negative electrode and a Lithium Metal Oxide (LMO) positive electrode. Each electrode has been simplified to 4 particles held together by binders and conductive agents. A graphitic carbon negative electrode is on the left and the LMO positive electrode is on the right where the top 2 particles are spinel structure and the bottom 2 particles are a layered structure for the purpose of illustrating different degradation mechanisms prevalent in certain crystalline structure.

In order to maximise the operational lifetime of a battery pack, it is clear that robust tools are needed that can determine the $\mathrm{SOH}$, based on a fundamental understanding of the underlying degradation mechanisms. There are various existing methodologies with their own advantages and disadvantages. A suitable method must be selected depending on the required output and available equipment, time and measurable parameters. In practice, several monitoring methods might be combined to produce a more comprehensive understanding of measured parameters and generate complimentary information. 
Some common in-situ diagnosis methods include: SRCV [13-16], ICM [17,18], incremental voltage method (IVM) [19,20], EIS [13,14,21], nuclear magnetic resonance (NMR) spectroscopy [22] and x-ray computational tomography (XCT) [23-25]. Examples of ex-situ analysis include: x-ray diffraction (XRD) [14,16,26,27], X-ray photoelectron spectroscopy (XPS) [28,29], and scanning electron microscopy (SEM) [13,30-32].

Wu, Yufit et al. [11] presented a novel in-situ on-board diagnosis method termed DTV as a faster complementary tool to the existing in-situ methods.

Complementary to these measurement techniques, Dubarry et al. introduced a quantitative analysis method for degradation modes in lithium iron phosphate batteries [33]. The method used a mechanistic model to track changes in $\mathrm{dQ} / \mathrm{dV}$ peak areas to obtain information on battery degradation modes. Each peak represents a combined phase at both the negative and positive electrode. Compared to the common capacity and power fade metrics, Dubarry's method presents a more detailed way to categorise degradation modes into the loss of lithium inventory (LLI), loss of active materials (LAM), ohmic resistance increase (ORI), and/or faradaic rate degradation (FRD) .

Dubarry later used this same method [7] to determine the different dominating degradation modes between high energy and high power commercial lithium iron phosphate cells. Although the method provides a useful tool to track degradation modes quantitatively, the model requires accurate half-cell data for each electrode and requires comparison and discussion of the results through separate in-situ methods or literature review as the model simulation may sometimes fit the $\mathrm{dQ} / \mathrm{dV}$ curve to several different combinations of degradation modes.

Han et al. [18] later expanded the dQ/dV analysis to other chemistries such as carbon-LMO and LTO-NMC without the mechanistic model to qualitatively estimate degradation modes in cycled commercial cells.

There is a clear need for an in-situ diagnosis method that can measure and decouple specific degradation modes in individual electrodes. Together with a fundamental understanding in battery degradation mechanisms, it is possible to use the same method as a prognosis to maximise cell lifetime by adapting and optimising its operating conditions. Ideally the technique should only require easily measurable parameters and little computation for it to be applicable as an on-board tool for example in an electric vehicle application.

\section{DTV CONCEPT}

Reynier et al. [34] demonstrated that entropy profiles have sharp features at stage transitions in well graphitized material. Maher and Yazami [35] later stated that for a graphite negative electrode and LCO positive electrode cell, the entropy profile undergoes significant changes at specific OCPs/SOCs under cycling and that these entropic changes can be attributed to degradation in specific electrodes. They concluded in their work that entropic changes at high potential (OCP value of $4.075 \mathrm{~V}, 4.05 \mathrm{~V}$ and $3.95 \mathrm{~V}$ ) are due to the crystal structure transformation of LCO positive electrodes and low potential staging phenomena in graphitic negative electrodes. 
Entropy is a direct function of temperature and the concept of DTV is that, by taking the temperature profile of the cell surface during galvanostatic charge/discharge, it is possible to obtain information on the entropic behaviour of the cell in a controlled environment. DTV requires voltage and temperature measurements only. Temperature can be measured using simple thermocouples or a thermal imaging camera. The DTV parameter is calculated by the ratio of the temperature and voltage differentials.

$D T V=\frac{d T}{d t} / \frac{d V}{d t}=\frac{d T}{d V}$

The DTV parameter is then plotted against cell potential to obtain information on the state-ofhealth of the cell. Similar to SRCV and ICM, the peaks in the profile represent stages of lithium (de)intercalation in the full cell which affect the amount of entropic heat generated and rate of change of cell potential. Peak evolutions in DTV under capacity fade can provide complementary information on specific degradation mechanisms to that of $\mathrm{dQ} / \mathrm{dV}$, as shown later in this paper.

DTV has a number of unique advantages compared to the existing in-situ methods. Crucially DTV includes additional entropic information that cannot be obtained directly through EIS, SRCV or ICM as seen in the results of this paper.

DTV does not require the isothermal conditions which are normally required in the other methods to obtain accurate diagnosis instead it relies upon the cell temperature changing during discharge/charge. Notably this means that, for DTV to be effective, the heat flux to the surroundings must be minimal compared to the rate of heat generation that dominates the $\mathrm{dT} / \mathrm{dV}$ term. These conditions are easily met if the test is started with the cell at ambient temperature and modest $\mathrm{C}$ rates are used, as heat flux from the cell will only begin to affect the results if the cell temperature rises significantly above ambient. In a real application it may therefore be necessary to regulate a thermal management system in order to allow the rate at which the cell is heating up/cooling down to be measured.

\section{EXPERIMENTAL}

\subsection{Controlled ACCELERATED AGEING}

In order to validate the concept, accelerated ageing experiments were carried out on commercial 5Ah lithium-ion cells. The cells used in this study contained a carbon negative electrode and NMC positive electrode of which the exact stoichiometric composition is unknown. The cells were stored at $10^{\circ} \mathrm{C}$ before use and then operated at different temperatures and different load profiles as shown in Table 1 to accelerate ageing and identify what diagnosis result is seen from cells aged with different expected degradation mechanisms [6].

Table 1. Accelerated ageing experiment

\begin{tabular}{lll}
\hline Cell & Load & Temperature \\
\hline 1 & Held at constant 4.2 V & $55^{\circ} \mathrm{C}$ \\
2 & 5 A $(\approx 1 \mathrm{C})$ cycling & $55^{\circ} \mathrm{C}$ \\
3 & 5 A $(\approx 1 \mathrm{C})$ cycling & Ambient \\
\hline
\end{tabular}


For the cells operated or stored at high temperature, they were placed inside a thermal chamber (ESCO Isotherm 32L) under forced air convection at $55^{\circ} \mathrm{C}$. The cells were characterised at room temperature of $20^{\circ} \mathrm{C}+/-2^{\circ} \mathrm{C}$ every 50 cycles using 4 diagnosis methods: EIS, SRCV, ICM and DTV.

Load cycling consisted of $1 \mathrm{C}$ charge followed by constant voltage charge with cut-off current at $250 \mathrm{~mA}$ and 10 minutes relaxation phase then $1 \mathrm{C}$ discharge and 10 minutes relaxation phase.

\subsection{DATA PROCESSING}

In order to obtain useable information the temperature measurements had to be smoothed appropriately as the temperature rise measured between each recording was considerably noisy. Smoothing was carried out carefully through a combination of Savitzky-Golay and moving average. The smoothed dT/dt data was compared back to the original temperature data set to check whether the smoothed data still accurately followed the original data. This was done by ensuring that the median of the absolute deviations of recorded dataset about the smoothed line is below $<0.3 \%$.

\subsection{VAlidation Of Method On A Cell With UnKNown History}

In order to validate the use of DTV as a diagnosis tool, the method was also applied to a fresh and an aged $25 \mathrm{Ah}$ large form factor pouch lithium-ion cells of unknown degradation history. The tested 25 Ah cells were made by the same manufacturer and with the same cell chemistry as the $5 \mathrm{Ah}$ cell.

It is known that a cell may have a temperature variation depending on the internal configuration of the cell [36]. In addition to surface thermocouples the cell temperature was monitored using a thermal imaging camera (model A655sc by FLIR Systems) to see if there was a difference in the DTV diagnosis depending on the physical position of temperature measurement, i.e. to see if spatially unequal degradation had occurred.

The cell surface, including tab connections were spray painted black and placed inside a painted box to give uniform infrared emissivity for thermal imaging camera measurement, and the thermal imaging camera temperature was checked against the thermocouples.

\section{RESULTS AND DISCUSSION}

\subsection{CAPACITY FADE}

The capacity fade of the cells, shown in Figure 2, were taken from the loss of Ah compared to the Ah measured when the cell was fresh. The capacity was determined from a slow rate voltage scan of $-150 \mu \mathrm{V} / \mathrm{s}$ between $4.2 \mathrm{~V}$ and $2.7 \mathrm{~V}$. The tests were carried out on all 3 cells at every 50 cycles. The change in the results between 300 and 350 cycles were likely to be due to the fact that the ambient lab temperature had dropped from $20^{\circ} \mathrm{C}$ to $18^{\circ} \mathrm{C}$ for the characterisation tests. The temperature in the thermal chambers was not affected, and therefore the actual degradation experiments were not affected, hence the return to trend once the next characterisation tests were performed at the correct temperature. 


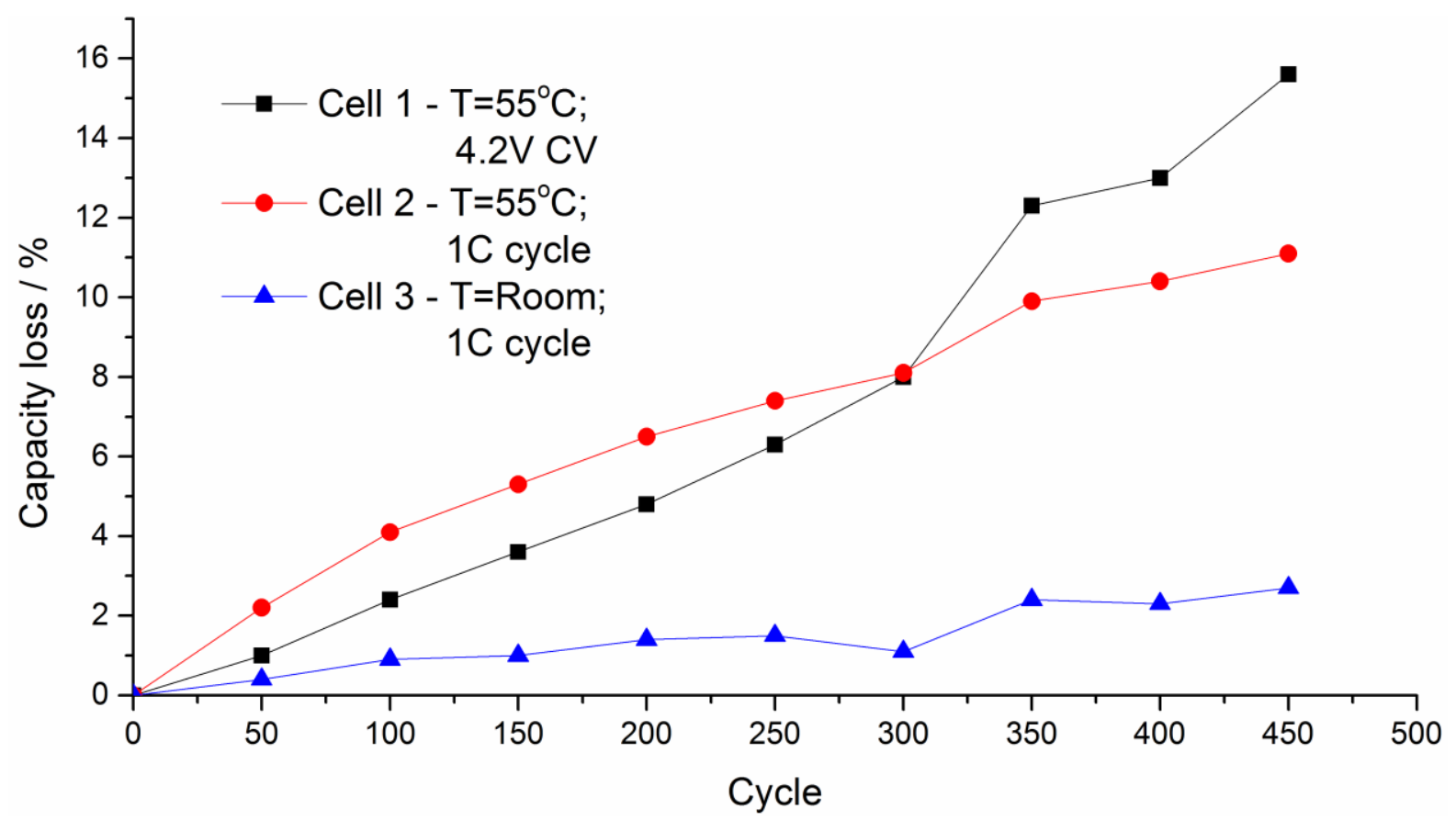

Figure 2. Capacity loss measurement of the three cells under accelerated degradation.

As seen from the capacity curve, cell 1 (held at high potential \& temperature) shows initially lower capacity loss which increases, whilst cell 2 (1 C cycling at high temperature) initially shows higher capacity loss which decreases over time. Cell 3 (1 C cycling at ambient temperature) shows very little capacity loss relative to the other cells as suggested due to lower reaction kinetics [6]. Further discussion will focus on analysing the two cells held at higher temperature due to their significant degradation.

\subsection{ELECTROCHEMICAL IMPEDANCE SPECTROSCOPY}

The impedance of the cells was measured every 50 cycles using a 4 channel Bio-logic VSP with a $5 \mathrm{~A}$ booster. The EIS tests were carried out at $5 \mathrm{~A}$ constant current load and $\mathrm{AC}$ amplitude of $0.2 \mathrm{~A}$ rms at between $2 \mathrm{kHz}$ and $1 \mathrm{~Hz}$ with 6 measurements per decade at different voltages from $4.2 \mathrm{~V}$ to $2.7 \mathrm{~V}$ at ambient temperature under fan forced convection to avoid different impedance responses [37]. EIS measurements were recorded sufficiently fast so that there was no significant change in SOC during the experiments. The resulted impedance spectra were fitted with an equivalent circuit model (ECM) as shown in Figure 3a using the software ZView (Scribner).

Figure $3 \mathrm{~b}$ shows the resistance parameter values of the two cells at various stages of capacity loss. It describes the progression of three resistance components: series, medium and low frequency. Medium frequency RC pair is often associated with lithium ion transport at the SEI layer and low frequency RC pair with charge transfer at the electrode/electrolyte interface $[14,38]$. A steady increase in all resistance parameters can be seen in both cells. The cause of this impedance rise is a combination of various degradation mechanisms [6]. 


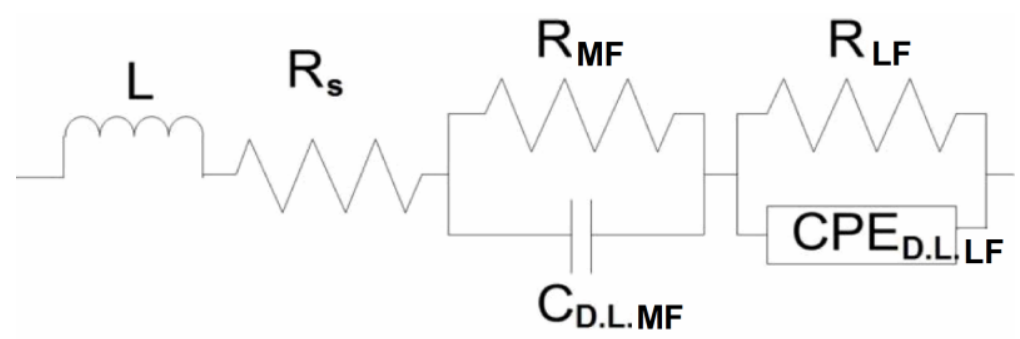

(a)

Cell 1

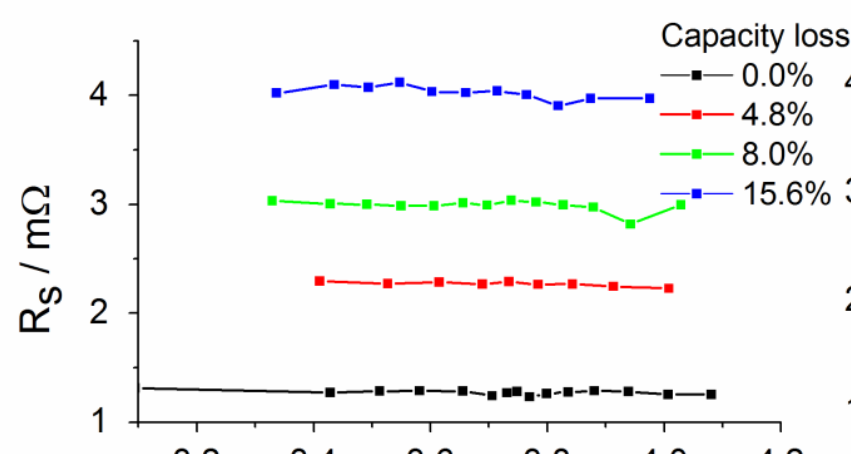

Cell 2
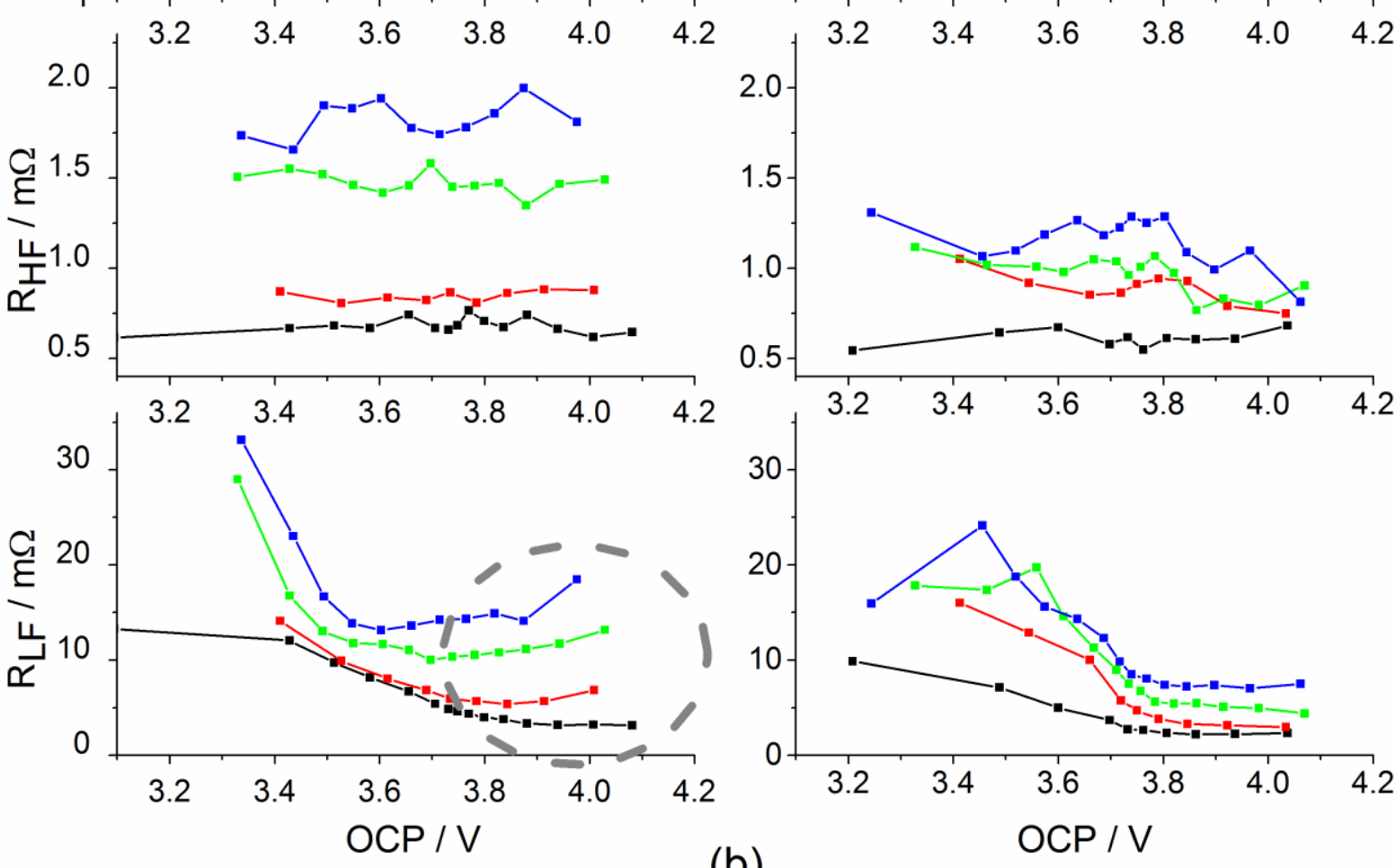

(b)

Figure 3. (a) Equivalent circuit model used. (b) Resistance parameters determined from impedance curve fitting at various stages of capacity fade. From top to bottom: series resistance, medium frequency (MF) resistance and low frequency (LF) resistance. Cell held at high potential (left) and cycled cell (right). Grey dashed circle highlights positive-electrode impedance shifting to lower potentials. 

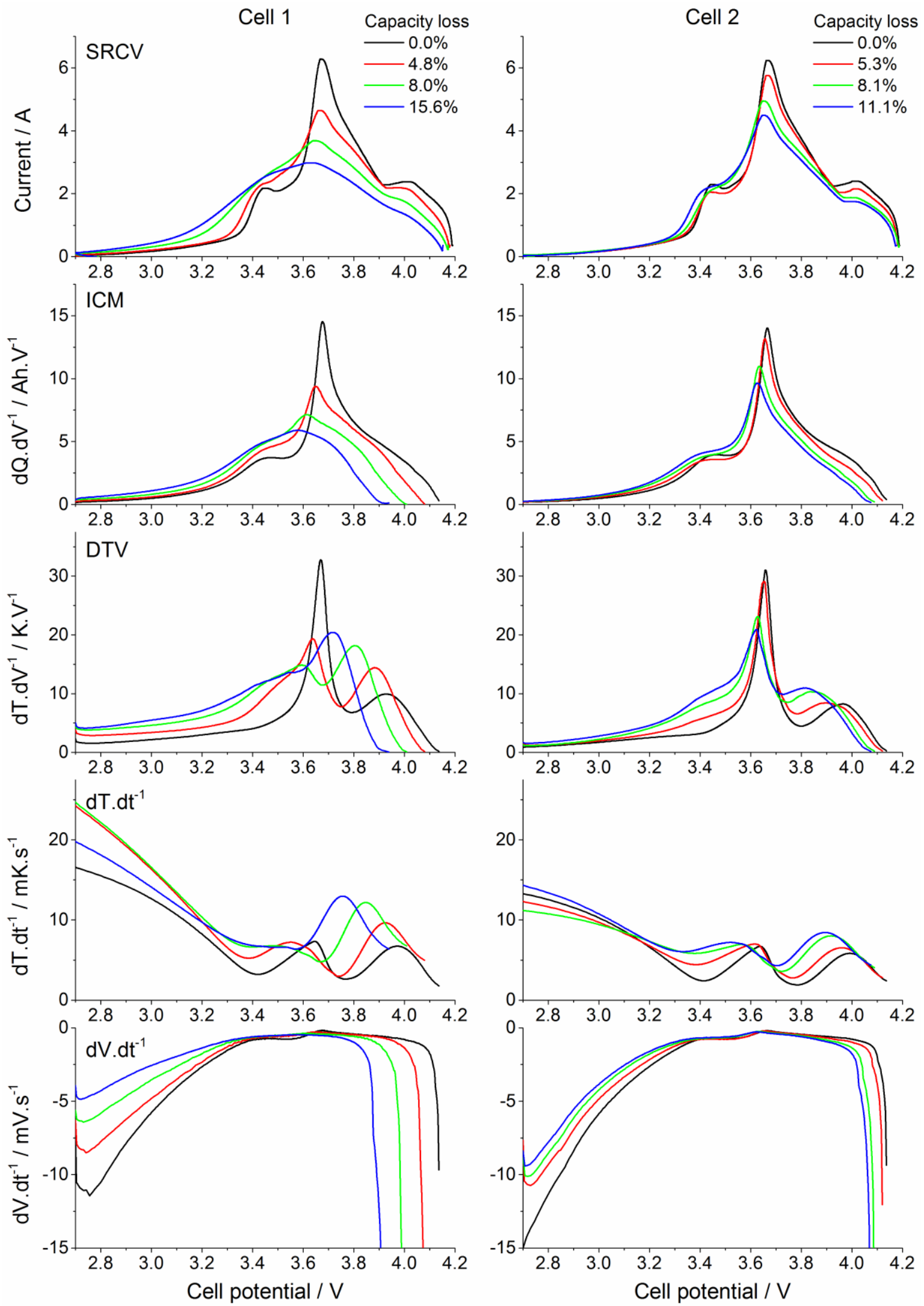

Figure 4. SRCV, ICM, DTV, $d T / d t$ and $d V / d t$ results for the two cells at different stages of capacity fade. Cell held at $4.2 \mathrm{~V}$ on the left. Cycled cell on the right. SRCV at $-150 \mu \mathrm{V} / \mathrm{s}$. ICM, DTV, dT/dt and $d V / d t$ carried out simultaneously at $2 C$ discharge. 


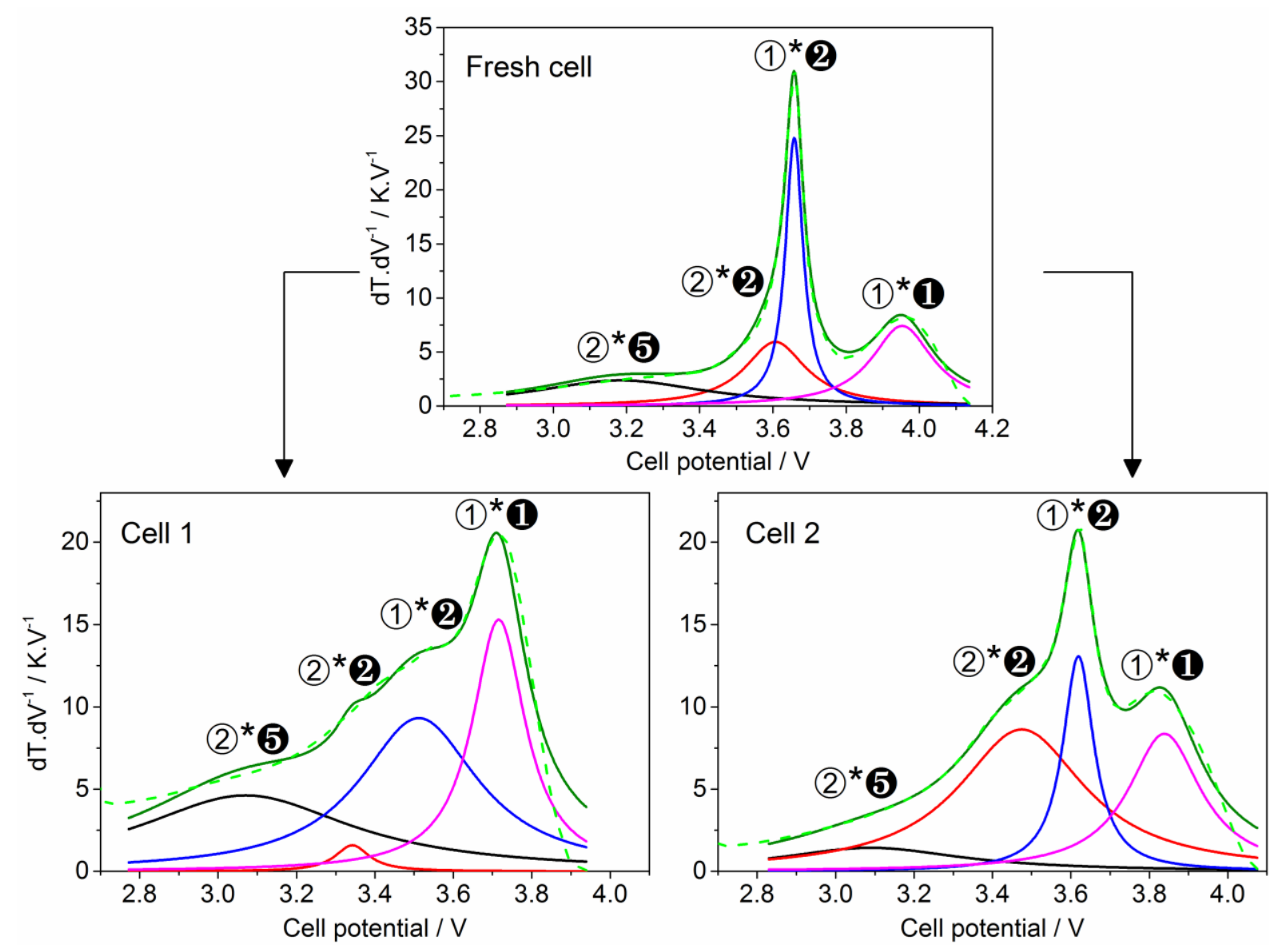

Figure 5. Peak fitting using MATLAB. DTV results for a fresh cell and aged 5Ah cells. Solid green line is sum of fitted peaks. Dashed green line is the original DTV measurement.

\subsection{Slow-RATE Cyclic Voltammetry, InCREMENTAL CAPACITY AND \\ DIFFERENTIAL THERMAL VOLTAMMETRY}

Figure 4 shows the results from SRCV, ICM and DTV for the two cells. SRCV was carried out at a voltage scan of $-150 \mu \mathrm{V} / \mathrm{s}$ between $4.2 \mathrm{~V}$ and $2.7 \mathrm{~V}$. ICM and DTV were carried out simultaneously at $10 \mathrm{~A}(2 \mathrm{C})$ constant current discharge at room temperature. $2 \mathrm{C}$ was chosen in this case as a suitable balance between speed of testing and clarity of entropic contribution within mixed heat generation of enthalpy and entropy [11].

It can be seen that SRCV and ICM generate curves with similar peak positions and shapes. It can be noted that the peak position of ICM (and DTV) results are shifted towards lower potential compared to SRCV. This is due to the greater overpotentials as result of higher testing currents. The term overpotential is used in this paper to describe the difference in the observed voltage from the thermodynamic potential of the cell. The SRCV result shown here was obtained in 180 minutes whereas the ICM and DTV took 30 minutes. It is possible to see from these results that ICM can give information comparable to SRCV in a reduced measurement time.

ICM, or $\mathrm{dQ} / \mathrm{dV}$ method, is carried out at a constant current hence the term "dQ/dt" is a constant. This means that $d Q / d V$ is essentially showing information on the differential voltage, $d V / d t$, alone. The differential of temperature, $\mathrm{dT}$, provides information on the entropic behaviour of the cell and is not constant through charge/discharge as seen in Figure 4. It can already be 


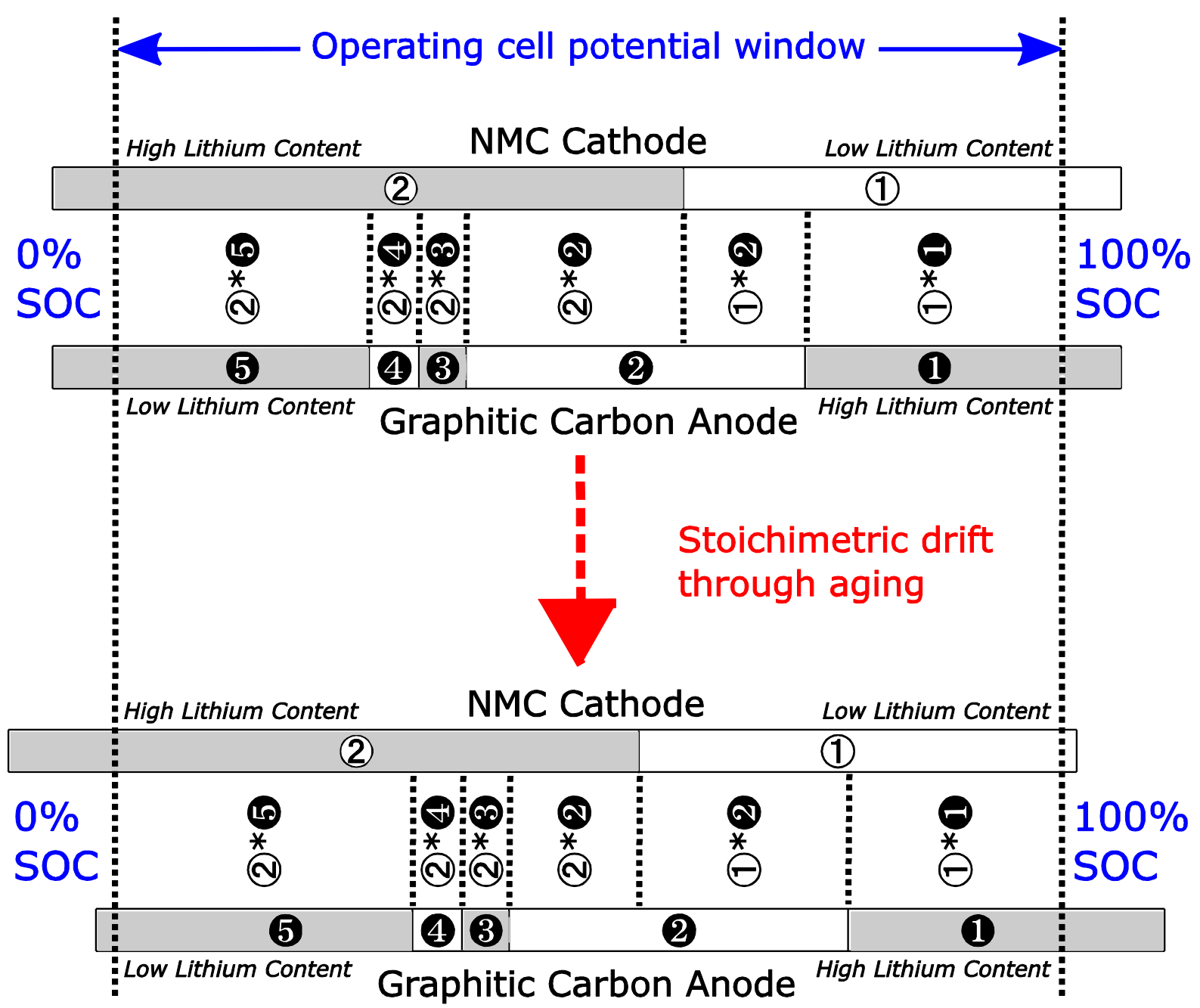

Figure 6. Schematic of combined phase transitions in graphitic carbon negative electrode and NMC positive electrode. Figure modified from [41] with different positive electrode chemistry and addition of effect of stoichiometric drift through ageing.

observed that the cells have different entropic behaviour at similar stages of capacity loss depending on its ageing history. Hence, it can be said that DTV provides similar information as $\mathrm{dQ} / \mathrm{dV}$ with the addition of entropic information about the cell.

In order to analyse the result quantitatively, the DTV curve was decoupled into 4 peaks using the open code "peakfit.m" on MATLAB $[39,40]$. Figure 5 shows example decoupling of peaks. Using the MATLAB code, the peaks were set to be Lorentzian for the best accuracy of fit and quantitative information for individual peaks was obtained for analysis such as: peak position, height, width and area under the peak. The width was calculated at the half height of the peak.

Dubarry et al. [41] has shown that each peak in a dQ/dV curve represents a particular phase of the negative and positive electrodes combined. Aurbach et al. [42] states that there are five stages of lithium intercalation where phase transitions occur in between (labelled in this paper as 1 to (5). Others show a transition over two hexagonal phases for an NMC positive electrode below $4.2 \mathrm{~V}[43,44]$. Yabuuchi et al. [45] identifies three distinct stages of lattice parameter evolution during lithiation of an NMC electrode material. The three stages were referred to solid-state redox reactions at specific peak potentials: $4.62 \mathrm{~V}, 4.01 \mathrm{~V}$ and $3.76 \mathrm{~V}$. Given that the 
Cell 1
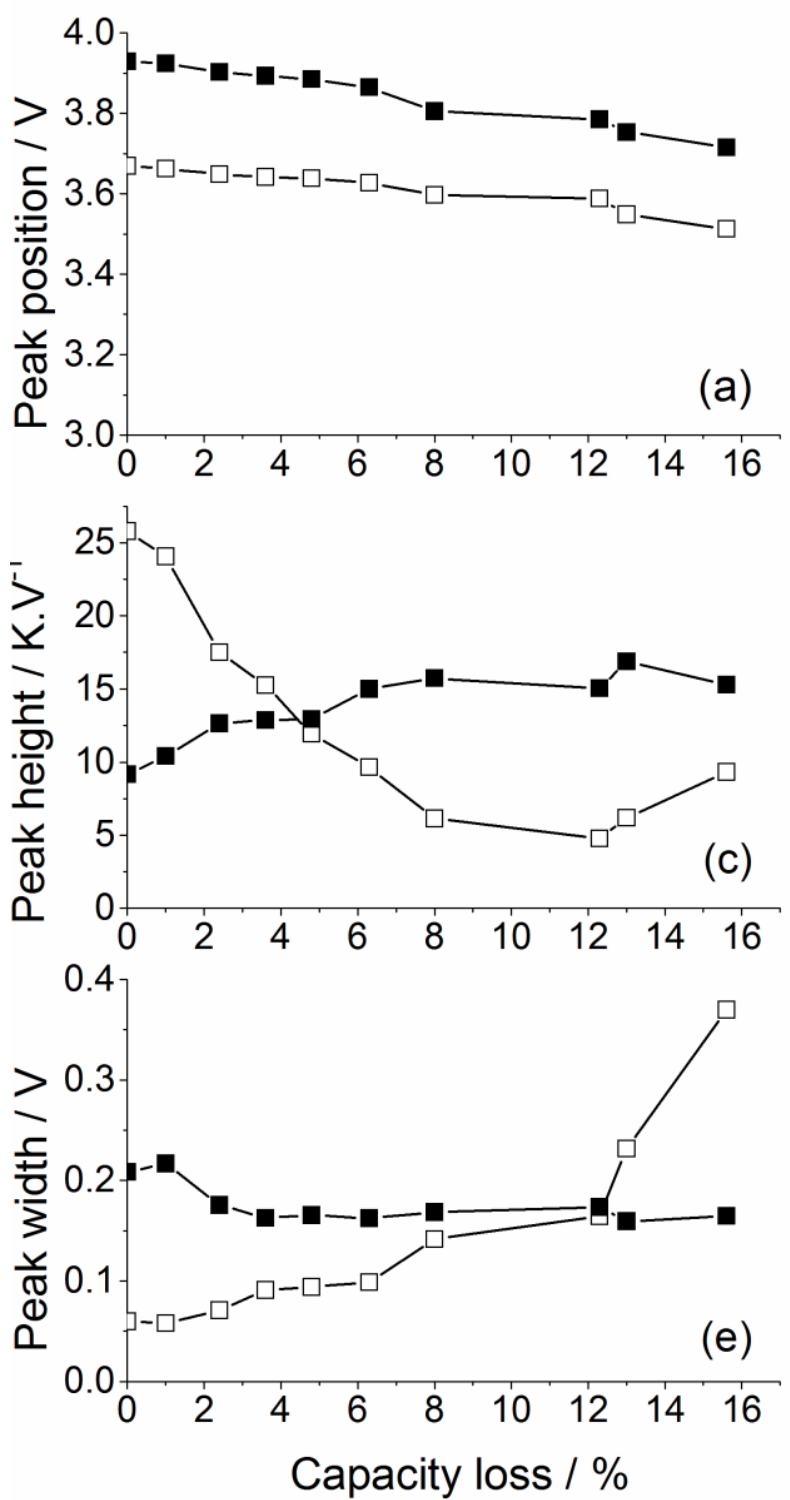

Cell 2
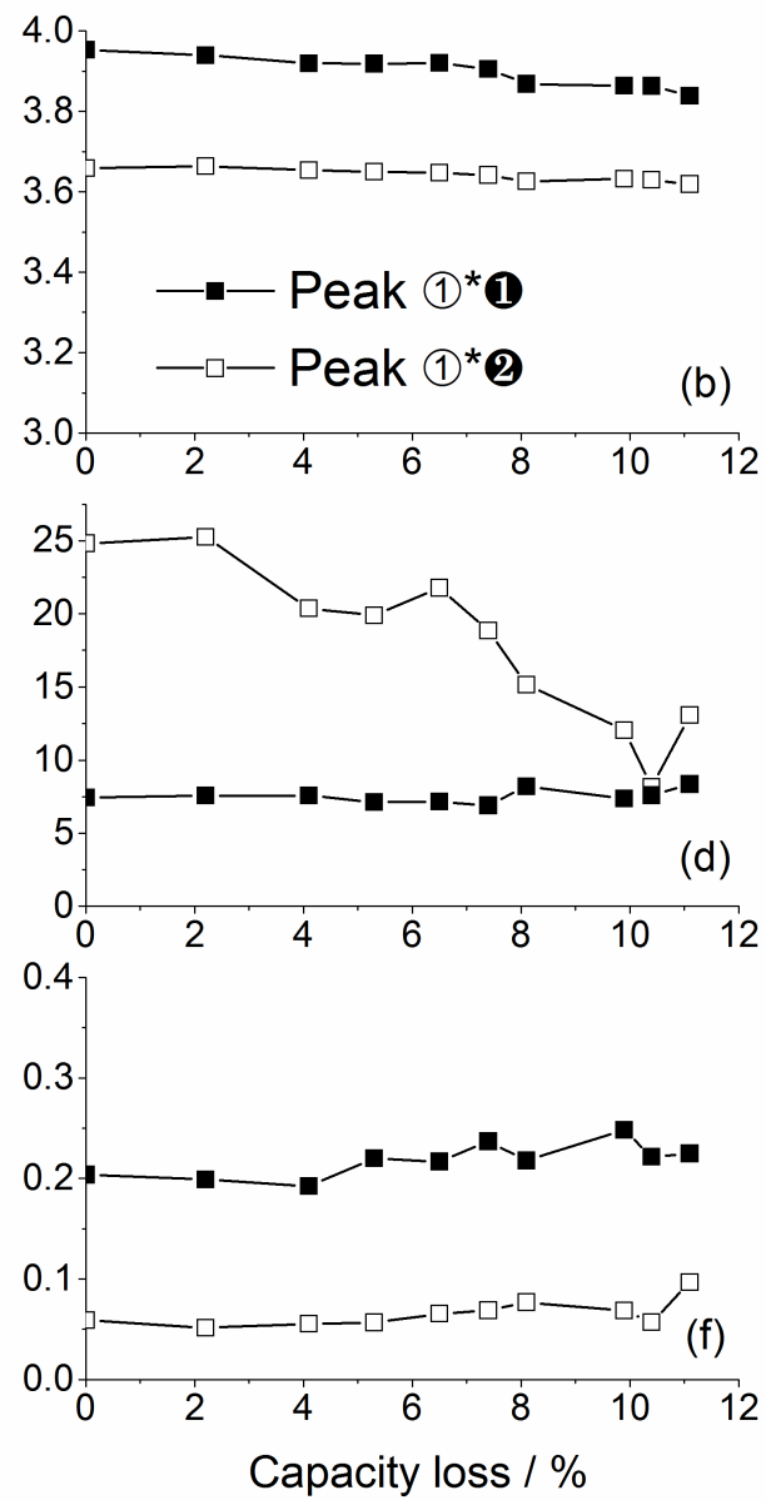

Figure 7. Peak parameter evolutions for the two cells stored at high temperature. Cell stored at high potential on the left. Cycled cell displayed on the right. Peak position ( $a-b)$, peak height (c-d) and peak width (e-f) are shown. Evolution in peak position and height gives information on impedance changes. Peak position and width gives indications on the stoichiometric drift in the cell.

redox reaction at $4.62 \mathrm{~V}$ is above the operating cell potential, the two remaining reactions can be associated with the changes in the hexagonal lattice parameter during cell discharge (labelled (1) and (2)). Despite the exact composition of the NMC electrode unknown, the data fit the same solid-state redox reactions and their peak potentials:

(1): $\mathrm{Li}_{1 / 3} \mathrm{Co}_{1 / 3} \mathrm{Ni}_{1 / 3} \mathrm{Mn}_{1 / 3} \mathrm{O}_{2}+1 / 3 \mathrm{Li} \rightarrow \mathrm{Li}_{2 / 3} \mathrm{Co}_{1 / 3} \mathrm{Ni}_{1 / 3} \mathrm{Mn}_{1 / 3} \mathrm{O}_{2}$ (at $\mathrm{E}=4.01 \mathrm{~V}$ vs. Li)

(2) $: \mathrm{Li}_{2 / 3} \mathrm{Co}_{1 / 3} \mathrm{Ni}_{1 / 3} \mathrm{Mn}_{1 / 3} \mathrm{O}_{2}+1 / 3 \mathrm{Li} \rightarrow \mathrm{LiCo}_{1 / 3} \mathrm{Ni}_{1 / 3} \mathrm{Mn}_{1 / 3} \mathrm{O}_{2}$ (at $\mathrm{E}=3.76 \mathrm{~V}$ vs. Li) 
Following Dubarrys's approach, each peak in DTV (and ICM) can be attributed to particular phases for the combined cell as presented in Figure 5 and 6. Peaks (2)*(3) and (2)*(4) are not shown/visible in the results. This is expected as the entropic heat generation of lithium intercalation stages 3 and 4 are very small compared to the other stages [42]. Hence the two peaks are masked under the surrounding peaks and would require more precise measurements to be resolved.

The peaks with greatest change in the peak parameters are of particular interest to diagnose the degraded cells. In this case, this is peak (1)*1 and (1)*2. It should be noted that these are not clear in either the SRCV or ICM techniques. Figure 7 describes the peak evolution of the two cells. All peak positions shows a steady shift to lower potentials which can be explained by the greater overpotential of the cells during discharge due to the increasing cell impedance as seen through the EIS measurements. The peak height shows interesting differences between the two cells. For the cycled cell, peak (1)*(1) shows negligible change and peak (1)*2 has an almost linear decrease. However, for the cell held at high potential, peak (1)*1 has significant increase in peak height and peak (1)*2 has a rapid decline initially but eventually slows down and rises back up. The cycled cell also has no significant change in peak width whereas the high potential cell has a decreasing peak width for peak (1)*1 and an increase for peak (1)*2 which eventually becomes wider than peak (1)*1. It naturally follows for the peak area to demonstrate a combined trend of peak height and width.

The question is what is the physical meaning of these peak parameters? Peak position describes the peak potential at which the (de)intercalation stages are occurring. The shift in the peak position through ageing can describe both the impedance rise of the cell [17] and stoichiometric drift (referring to Figure 6, it relates to the misbalancing of the two electrodes through the change of the thermodynamic potential expressed by Nernst equation when the concentration of lithium in solid phase is changing as a result of the lithium inventory loss). Peak height indicates the point of maximum rate of heat generation for those phases. Peak width describes the potential window of the combined phases in the two electrodes. Peak area gives information on the heat generated during the (de)intercalation stages. Hence each peak parameter can provide information about the cell. As illustrated in Figure 6, stoichiometric drift will alter the potential windows of the combined phases. Therefore it is possible to monitor stoichiometric drift of combined electrodes through change in DTV peak width and its position.

\subsubsection{Cell Held at High Potential}

Based upon $[9,46,47]$, the cell held at high potential is likely to initially experience accelerated SEI layer growth caused by the low negative electrode potential and the high temperature (i.e. faster reaction kinetics and diffusion). The LLI and LAM consumed by the SEI will initially slowly shift the negative electrode stoichiometry to lower lithium content and therefore higher thermodynamic potential [48]. This can be seen by the increase in width of peak (1)*2 and decrease in peak (1)*1 (refer to Figure 6).

The stoichiometric drift in the negative electrode narrows the real safe operating potential in comparison to the safe operating potential recommended by the manufacturers [12]. As the negative electrode stoichiometry shifts to lower lithium content, the positive electrode becomes increasingly overcharged promoting positive-electrode material decomposition and metal dissolution $[27,49]$. This is then expected to lead to accelerating SEI layer growth due to metal 
deposition on the negative electrode as also seen from the capacity loss and EIS results $[6,50]$. The cell capacity experiences a slow initial rate of loss (SEI layer growth) that is increasing due to degradation of the positive electrode. In Figure $3 b$, an increase in impedance of the low frequency resistance at high potential is associated with positive electrode degradation which is not seen for the cycled cell. This is also reflected in the DTV results by the increase in height of peak (1)*1 i.e. increasing rate of heat generation during the (de)intercalation stages at high cell potential due to the increased impedance. Note how the peak (1)*2 height eventually also begins to rise as the positive-electrode impedance increases.

\subsubsection{CYCLED CELL}

Based upon [51-53], the cycled cell is likely to experience an initially faster rate of SEI growth compared to the cell held at constant potential due to the exposure of fresh electrode surface to the electrolyte as a result of cracks in the surface film caused by cycling [54]. However, the rate of degradation was expected to slow down as the SEI layer thickened [55]. This can be seen by the smaller shift in DTV peak positions corresponding to lower overpotential of the cycled cell. The same phenomena can also be observed in the capacity fade results, with the initial faster rate of capacity loss compared to cell 1 which then slows down as the rate of capacity fade for the high potential cell increases. This supports the hypothesis that the degradation process slows down as SEI grows thicker [46].

Due to the smaller LLI and LAM in the cycled cell, less stoichiometric drift is expected on the negative and positive electrode. This can be seen by the almost unchanged DTV peak widths in Figure 7. As the cycled cell spends less time at high potential, the positive electrode is not overcharged as often. This is confirmed from the peak height of peak (1)*1 which remained constant throughout capacity loss.

\subsection{VAliDATION EXPERIMENT - 25AH CELl of UnKNOWn DEGRADATION History}

Using the results obtained from the $5 \mathrm{Ah}$ data, another cell with unknown degradation history was examined to validate the presented novel application of DTV. A fresh and aged 25Ah lithium-ion cell with the same cell chemistry and manufacturer as the $5 \mathrm{Ah}$ cells were used.

The capacity fade of the aged cell was first determined. A 0.8 C slow CC discharge (20 A) has shown a $35.6 \%$ capacity fade compared to the fresh cell, and a significant rise in overpotential.

DTV at $1 \mathrm{C}$ was carried out while monitoring the cell surface temperature with a thermal imaging camera. 25Ah cell was ideal for this test due to its large imaging surface area. Figure 8a shows the DTV results for the fresh and aged cell with decoupled peaks.

The DTV results were checked for different locations on the cell surface however there were no significant differences in the results in this case. Therefore, either the cell was uniformly degraded spatially, or the DTV technique with a thermal imaging camera may not be suitable for detecting all types of spatially unequal degradation. DTV peak heights were smaller towards the cell tabs due to passive cell tab cooling and also smaller on the negative electrode side as copper current collector is a better thermal conductor than aluminium on the positive electrode side. 

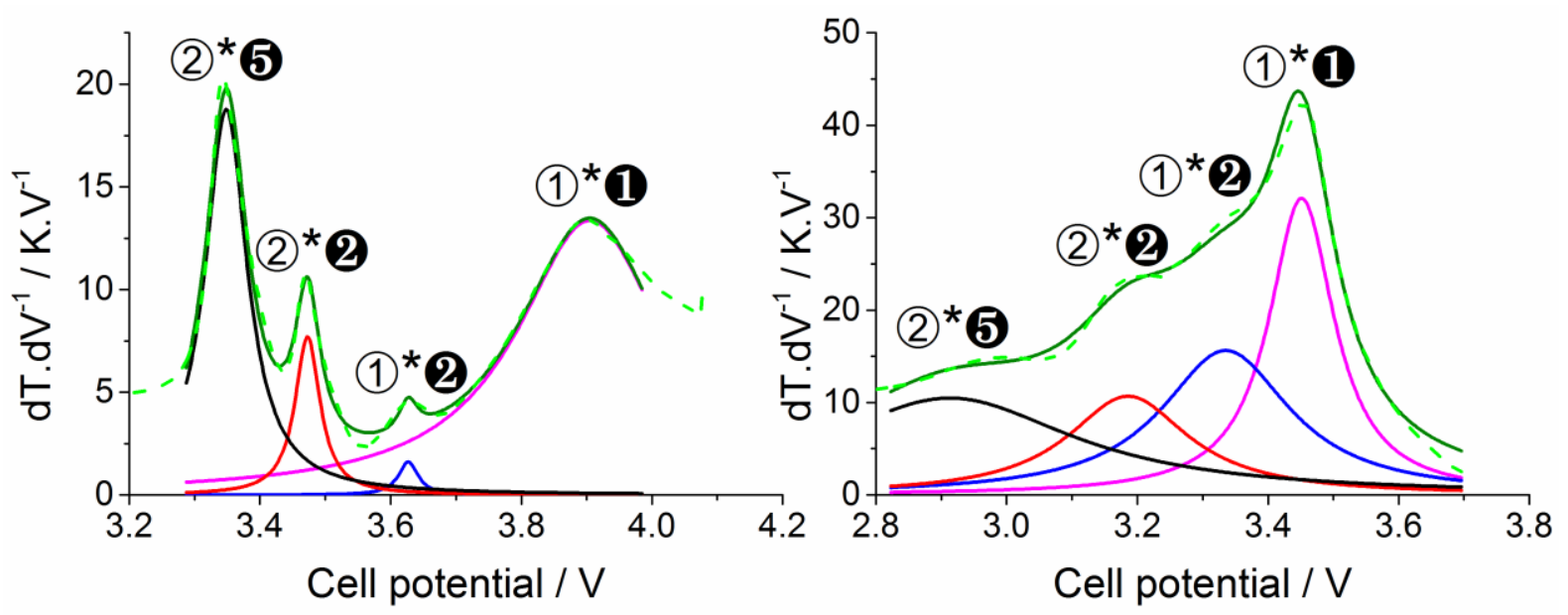

(a)
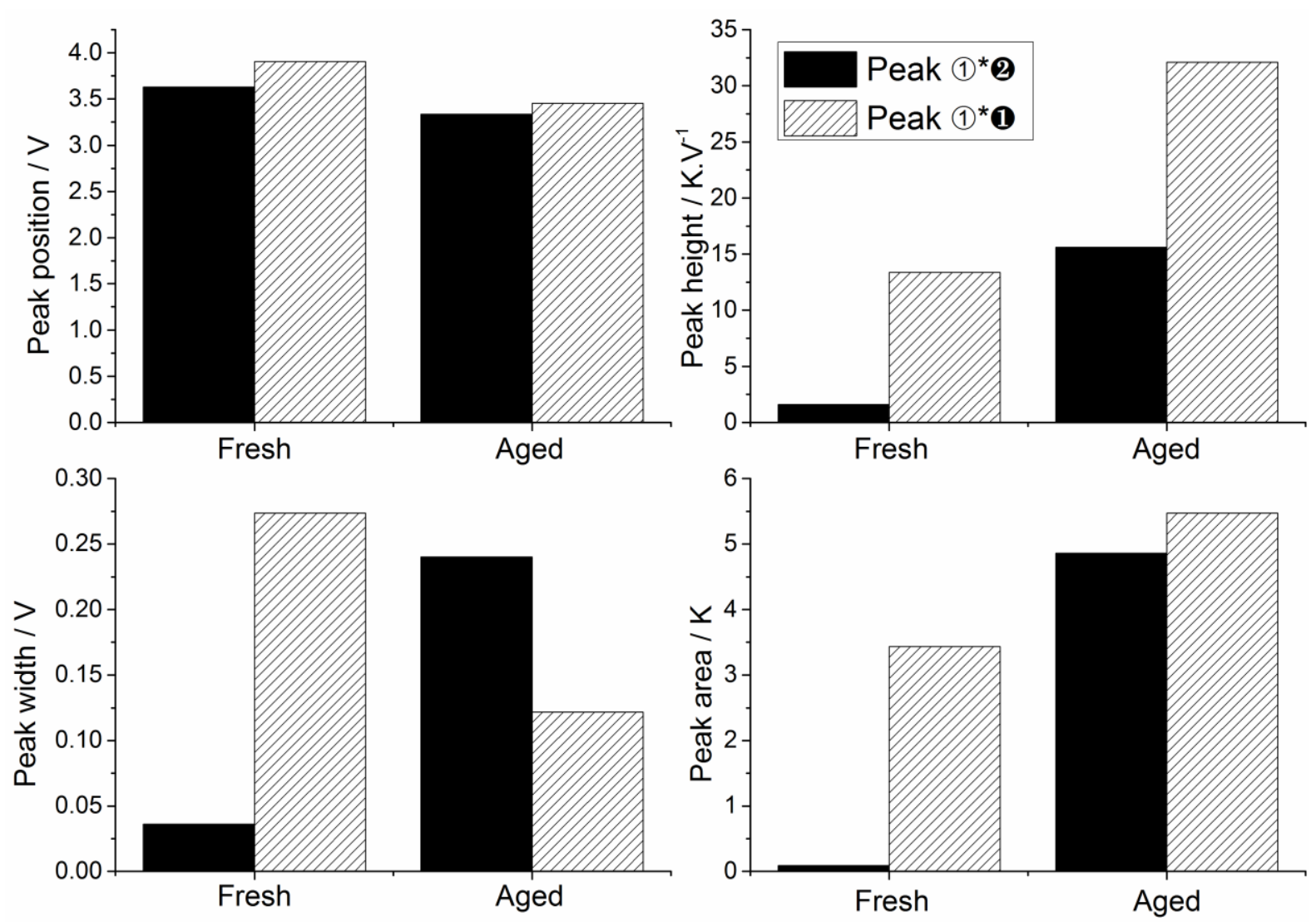

(b)

Figure 8. (a) DTV results for 25Ah fresh cell (left) and aged cell (right). Dotted green line is experimental DTV result and solid green line is the sum of fitted peaks. (b) Peak parameters for fresh and aged 25Ah cell.

The results suggest that the DTV spectrum for the aged cell has a striking resemblance to that of the $5 \mathrm{Ah}$ cell held at high potential (Figure 5). Both cells show 4 distinct peaks. The "fresh cell" DTV curve does not look similar to the $5 \mathrm{Ah}$ fresh cell however this is expected as the storage condition and time prior to experiment was unknown. 
The peaks can be decoupled and quantified using the same MATLAB method and the peak change can be calculated. Focusing on the same two peaks again for comparison with the $5 \mathrm{Ah}$ data, Figure $8 \mathrm{~b}$ shows the peak parameters for the fresh and aged cell.

Peak positions dramatically shifts to lower potentials. This gives information on the significant rise of the cell impedance. At this point, this power fade could be a result of combination of various degradation mechanisms and it is hard to pinpoint a dominating mode.

Focusing on peak width, peak (1)*(1) has decreased and peak (1)*2 has increased. The change is so significant that peak (1)*2 has become wider than peak (1)*1. This is the same observation as for the $5 \mathrm{Ah}$ cell held at high potential and infers the existence of dominating negative electrode stoichiometric drift. From this result, it can be hypothesised that the impedance rise seen through peak position is likely to be due to severe SEI layer formation.

For peak height, both see significant increases where peak (1)*(1) has a greater change. This can be explained by the increased impedance at high potentials due to the shifting of positiveelectrode impedance to lower potentials. The profile of this impedance rise suggests high heat generation, i.e. peak height, for peak (1)*1 and less for peak (1)*2 which matches the result suggesting the degradation at the positive electrode.

Having analysed the DTV peaks quantitatively, it is shown that the 25 Ah aged cell has reached a similar state as the 5 Ah cell held at high potential. Through individual peak parameter observation, it can be estimated that there is a substantial negative electrode stoichiometric drift through SEI layer growth and significant degradation at the positive electrode. It is difficult to predict the operational history from 2 data sets. However regardless of how it was aged it is possible to suggest unequivocally using the DTV diagnostic technique that the performance of the aged cell is limited mostly by the positive electrode and therefore should not be charged up to $4.2 \mathrm{~V}$.

\section{FUTURE WORK}

We propose that DTV could be used to continuously track how the maximum operating voltage should be de-rated over time to maximise lifetime, minimising accelerated degradation of the positive electrode. The de-rated voltage can be determined from observing the cell potential above which there is only negligible heat generation.

The use of thermal imaging camera will be beneficial to study large form-factor cells provided there will be a spatially unequal degradation.

\section{CONCLUSION}

DTV method has been demonstrated to be very useful in order to diagnose the state of health of a lithium ion battery with far more fidelity than common capacity fade measurements, using cost-effective thermocouples under natural convection environment on a lab bench.

The method has been presented in this paper as a battery diagnosis method to compliment SRCV and dQ/dV. It is faster than SRCV and provides similar results as dQ/dV but with the 
additional entropic term. DTV is also simple to compute unlike parameterising an equivalent circuit model from EIS data. The use of a thermal imaging camera was also demonstrated.

Three cells (graphitic carbon negative electrode - NMC positive electrode) were placed under different accelerated ageing experiments including high temperature, cycling and high potential hold. The cells were analysed regularly to track specific degradation modes. DTV peaks, representing (de)intercalation stages of lithium in both electrodes, were decoupled using MATLAB to quantitatively analyse the peak evolutions over various stages of capacity loss. DTV was able to support in-depth hypotheses for the SOH of the degraded cells collectively and compared with the other mentioned methods.

The DTV information obtained from the controlled degradation experiment was then applied to an aged cell of unknown history. DTV was able to present a diagnosis for the cell no longer relying on collective information from other methods.

\section{ACKNOWLEDGEMENT}

The authors would also like to acknowledge Climate KIC for funding this work for Yu Merla as well as the EPSRC through the Career Acceleration Fellowship for Gregory Offer (EP/I00422X/1) and Low Carbon Grids Project (EP/K002252/1) for Billy Wu, the ESRN Energy Storage Research Network project for Vladimir Yufit and the FUTURE vehicles project (EP/I038586/1) and Johnson Matthey Battery Systems for providing the cells.

\section{REFERENCES}

[1] A. Barré, B. Deguilhem, S. Grolleau, M. Gérard, F. Suard, D. Riu, A review on lithium-ion battery ageing mechanisms and estimations for automotive applications, J. Power Sources. 241 (2013) 680-689. doi:10.1016/j.jpowsour.2013.05.040.

[2] D. Miranda, C.M. Costa, Lithium ion rechargeable batteries : State of the art and future needs of microscopic theoretical models and simulations, J. Electroanal. Chem. 739 (2015) 97-110. doi:10.1016/j.jelechem.2014.12.010.

[3] W. Waag, C. Fleischer, D. Uwe, Critical review of the methods for monitoring of lithiumion batteries in electric and hybrid vehicles, J. Power Sources. 258 (2014) 321-339. doi:10.1016/j.jpowsour.2014.02.064.

[4] M.B. Pinson, M.Z. Bazant, Theory of SEI Formation in Rechargeable Batteries: Capacity Fade, Accelerated Aging and Lifetime Prediction, J. Electrochem. Soc. 160 (2012) A243A250. doi:10.1149/2.044302jes.

[5] J. Christensen, J. Newman, A Mathematical Model for the Lithium-Ion Negative Electrode Solid Electrolyte Interphase, J. Electrochem. Soc. 151 (2004) A1977. doi:10.1149/1.1804812.

[6] J. Vetter, P. Novák, M.R. Wagner, C. Veit, K.-C. Möller, J.O. Besenhard, et al., Ageing mechanisms in lithium-ion batteries, J. Power Sources. 147 (2005) 269-281. doi:10.1016/j.jpowsour.2005.01.006.

[7] M. Dubarry, C. Truchot, B.Y. Liaw, Cell degradation in commercial LiFePO4 cells with high-power and high-energy designs, J. Power Sources. 258 (2014) 408-419. doi:10.1016/j.jpowsour.2014.02.052. 
[8] F. Tariq, V. Yufit, D.S. Eastwood, Y. Merla, M. Biton, B. Wu, et al., In-Operando X-ray Tomography Study of Lithiation Induced Delamination of Si Based Anodes for LithiumIon Batteries, ECS Electrochem. Lett. 3 (2014) A76-A78. doi:10.1149/2.0081407eel.

[9] B. Scrosati, J. Garche, Lithium batteries: Status, prospects and future, J. Power Sources. 195 (2010) 2419-2430. doi:10.1016/j.jpowsour.2009.11.048.

[10] M. Wohlfahrt-Mehrens, C. Vogler, J. Garche, Aging mechanisms of lithium cathode materials, J. Power Sources. 127 (2004) 58-64. doi:10.1016/j.jpowsour.2003.09.034.

[11] B. Wu, V. Yufit, Y. Merla, R.F. Martinez-botas, N.P. Brandon, G.J. Offer, Differential thermal voltammetry for tracking of degradation in lithium-ion batteries, J. Power Sources. 273 (2015) 495-501. doi:10.1016/j.jpowsour.2014.09.127.

[12] S. Krueger, R. Kloepsch, J. Li, S. Nowak, S. Passerini, M. Winter, How Do Reactions at the Anode/Electrolyte Interface Determine the Cathode Performance in Lithium-Ion Batteries?, J. Electrochem. Soc. 160 (2013) A542-A548. doi:10.1149/2.022304jes.

[13] B. Stiaszny, J.C. Ziegler, E.E. Krauß, M. Zhang, J.P. Schmidt, E. Ivers-Tiffée, Electrochemical characterization and post-mortem analysis of aged LiMn 204-NMC/graphite lithium ion batteries part II: Calendar aging, J. Power Sources. 258 (2014) 61-75.

doi:10.1016/j.jpowsour.2014.02.019.

[14] a. Vadivel Murugan, M.V. Reddy, G. Campet, K. Vijayamohanan, Cyclic voltammetry, electrochemical impedance and ex situ X-ray diffraction studies of electrochemical insertion and deinsertion of lithium ion into nanostructured organic-inorganic poly $(3,4-$ ethylenedioxythiophene) based hybrids, J. Electroanal. Chem. 603 (2007) 287-296. doi:10.1016/j.jelechem.2007.02.013.

[15] M.D. Levi, D. Aurbach, The mechanism of lithium intercalation in graphite film electrodes in aprotic media. Part 1 . High resolution slow scan rate cyclic voltammetric studies and modeling, J. Electroanal. Chem. 421 (1997) 79-88. doi:10.1016/S0022-0728(96)04832-2.

[16] M. V. Reddy, B. Pecquenard, P. Vinatier, a. Levasseur, Cyclic voltammetry and galvanostatic cycling characteristics of LiNiVO4 thin films during lithium insertion and re/de-insertion, Electrochem. Commun. 9 (2007) 409-415. doi:10.1016/j.elecom.2006.10.011.

[17] M. Dubarry, B.Y. Liaw, Identify capacity fading mechanism in a commercial LiFePO4 cell, J. Power Sources. 194 (2009) 541-549. doi:10.1016/j.jpowsour.2009.05.036.

[18] X. Han, M. Ouyang, L. Lu, J. Li, Y. Zheng, Z. Li, A comparative study of commercial lithium ion battery cycle life in electrical vehicle: Aging mechanism identification, J. Power Sources. 251 (2014) 38-54. doi:10.1016/j.jpowsour.2013.11.029.

[19] a. J. Smith, H.M. Dahn, J.C. Burns, J.R. Dahn, Long-Term Low-Rate Cycling of LiCoO2/Graphite Li-Ion Cells at 55 ${ }^{\circ}$ C, J. Electrochem. Soc. 159 (2012) A705. doi:10.1149/2.056206jes.

[20] a. J. Smith, N.N. Sinha, J.R. Dahn, Narrow Range Cycling and Storage of Commercial Li Ion Cells, J. Electrochem. Soc. 160 (2012) A235-A242. doi:10.1149/2.033302jes.

[21] a. Eddahech, O. Briat, E. Woirgard, J.M. Vinassa, Remaining useful life prediction of lithium batteries in calendar ageing for automotive applications, Microelectron. Reliab. 52 (2012) 2438-2442. doi:10.1016/j.microrel.2012.06.085.

[22] Y.-Y. Hu, Z. Liu, K.-W. Nam, O.J. Borkiewicz, J. Cheng, X. Hua, et al., Origin of additional capacities in metal oxide lithium-ion battery electrodes., Nat. Mater. 12 (2013) 1130-6. doi:10.1038/nmat3784.

[23] F. Tariq, V. Yufit, D.S. Eastwood, Y. Merla, M. Biton, B. Wu, et al., In-Operando X-ray Tomography Study of Lithiation Induced Delamination of Si Based Anodes for Lithium- 
Ion Batteries, ECS Electrochem. Lett. 3 (2014) A76-A78. doi:10.1149/2.0081407eel.

[24] M. Ebner, F. Marone, M. Stampanoni, V. Wood, Visualization and quantification of electrochemical and mechanical degradation in Li ion batteries., Science. 342 (2013) 716-20. doi:10.1126/science.1241882.

[25] D.P. Finegan, M. Scheel, J.B. Robinson, B. Tjaden, I. Hunt, T.J. Mason, et al., In-operando high-speed tomography of lithium-ion batteries during thermal runaway, Nat. Commun. 6 (2015) 6924. doi:10.1038/ncomms7924.

[26] H.M. Wu, J.P. Tu, Y.F. Yuan, Y. Li, X.B. Zhao, G.S. Cao, Electrochemical and ex situ XRD studies of a LiMn1.5Ni0.504 high-voltage cathode material, Electrochim. Acta. 50 (2005) 4104-4108. doi:10.1016/j.electacta.2005.01.026.

[27] J.C. Knight, S. Therese, a. Manthiram, Delithiation Mechanisms in Acid of Spinel LiMn2xMxO4 (M = Cr, Fe, Co, and Ni) Cathodes, J. Electrochem. Soc. 162 (2014) A426-A431. doi:10.1149/2.0661503jes.

[28] Y.-S. Su, Y. Fu, T. Cochell, A. Manthiram, A strategic approach to recharging lithiumsulphur batteries for long cycle life., Nat. Commun. 4 (2013) 2985. doi:10.1038/ncomms3985.

[29] C. Liu, H. Huang, G. Cao, F. Xue, R.A. Paredes Camacho, X. Dong, Enhanced Electrochemical Stability of Sn-Carbon Nanotube Nanocapsules as Lithium-Ion Battery Anode, Electrochim. Acta. 144 (2014) 376-382. doi:10.1016/j.electacta.2014.07.068.

[30] T. Waldmann, S. Gorse, T. Samtleben, G. Schneider, V. Knoblauch, M. Wohlfahrt-Mehrens, A Mechanical Aging Mechanism in Lithium-Ion Batteries, J. Electrochem. Soc. 161 (2014) A1742-A1747. doi:10.1149/2.1001410jes.

[31] F. Tariq, V. Yufit, M. Kishimoto, P.R. Shearing, S. Menkin, D. Golodnitsky, et al., Threedimensional high resolution X-ray imaging and quantification of lithium ion battery mesocarbon microbead anodes, J. Power Sources. 248 (2014) 1014-1020. doi:10.1016/j.jpowsour.2013.08.147.

[32] H. Qin, X. Zhao, N. Jiang, Z. Li, Solvothermal synthesis and ex situ XRD study of nanoNi3Sn2 used as an anode material for lithium-ion batteries, J. Power Sources. 171 (2007) 948-952. doi:10.1016/j.jpowsour.2007.05.097.

[33] M. Dubarry, C. Truchot, B.Y. Liaw, Synthesize battery degradation modes via a diagnostic and prognostic model, J. Power Sources. 219 (2012) 204-216. doi:10.1016/j.jpowsour.2012.07.016.

[34] Y.F. Reynier, R. Yazami, B. Fultz, Thermodynamics of Lithium Intercalation into Graphites and Disordered Carbons, J. Electrochem. Soc. 151 (2004) A422. doi:10.1149/1.1646152.

[35] K. Maher, R. Yazami, A study of lithium ion batteries cycle aging by thermodynamics techniques, J. Power Sources. 247 (2014) 527-533. doi:10.1016/j.jpowsour.2013.08.053.

[36] J.B. Robinson, J. a. Darr, D.S. Eastwood, G. Hinds, P.D. Lee, P.R. Shearing, et al., Nonuniform temperature distribution in Li-ion batteries during discharge - A combined thermal imaging, X-ray micro-tomography and electrochemical impedance approach, J. Power Sources. 252 (2014) 51-57. doi:10.1016/j.jpowsour.2013.11.059.

[37] D.P. Abraham, E.M. Reynolds, P.L. Schultz, a. N. Jansen, D.W. Dees, Temperature Dependence of Capacity and Impedance Data from Fresh and Aged High-Power LithiumIon Cells, J. Electrochem. Soc. 153 (2006) A1610. doi:10.1149/1.2210668.

[38] G.J. Offer, V. Yufit, D. a. Howey, B. Wu, N.P. Brandon, Module design and fault diagnosis in electric vehicle batteries, J. Power Sources. 206 (2012) 383-392.

doi:10.1016/j.jpowsour.2012.01.087. 
[39] T.C. O'Haver, peakfit.m, (n.d.). https://terpconnect.umd.edu/ toh/spectrum/peakfit.m (accessed May 6, 2015).

[40] C. Birkl, D. Howey, Degradation diagnostics for Li-ion batteries, in: Futur. Powertrain Conf., 2015.

[41] M. Dubarry, C. Truchot, M. Cugnet, B.Y. Liaw, K. Gering, S. Sazhin, et al., Evaluation of commercial lithium-ion cells based on composite positive electrode for plug-in hybrid electric vehicle applications. Part I: Initial characterizations, J. Power Sources. 196 (2011) 10328-10335. doi:10.1016/j.jpowsour.2011.08.077.

[42] D. Aurbach, B. Markovsky, I. Weissman, E. Levi, Y. Ein-Eli, On the correlation between surface chemistry and performance of graphite negative electrodes for Li ion batteries, Electrochim. Acta. 45 (1999) 67-86. doi:10.1016/S0013-4686(99)00194-2.

[43] W.S. Yoon, K.Y. Chung, J. McBreen, X.Q. Yang, A comparative study on structural changes of LiCo1/3Ni1/3Mn1/302 and LiNi0.8Co0.15Al0.0502 during first charge using in situ XRD, Electrochem. Commun. 8 (2006) 1257-1262. doi:10.1016/j.elecom.2006.06.005.

[44] K.-W. Nam, W.-S. Yoon, H. Shin, K.Y. Chung, S. Choi, X.-Q. Yang, In situ X-ray diffraction studies of mixed LiMn2O4-LiNi1/3Co1/3Mn1/302 composite cathode in Li-ion cells during charge-discharge cycling, J. Power Sources. 192 (2009) 652-659. doi:10.1016/j.jpowsour.2009.02.088.

[45] N. Yabuuchi, Y. Makimura, T. Ohzuku, Solid-State Chemistry and Electrochemistry of LiCo[sub 1/3] Ni[sub 1/3] Mn[sub 1/3] O[sub 2] for Advanced Lithium-Ion Batteries, J. Electrochem. Soc. 154 (2007) A314. doi:10.1149/1.2455585.

[46] X. Lin, J. Park, L. Liu, Y. Lee, a. M. Sastry, W. Lu, A Comprehensive Capacity Fade Model and Analysis for Li-Ion Batteries, J. Electrochem. Soc. 160 (2013) A1701-A1710. doi:10.1149/2.040310jes.

[47] E. Peled, The Electrochemical Behavior of Alkali and Alkaline Earth Metals in Nonaqueous Battery Systems-The Solid Electrolyte Interphase Model, J. Electrochem. Soc. 126 (1979) 2047. doi:10.1149/1.2128859.

[48] Q. Zhang, R.E. White, Calendar life study of Li-ion pouch cells. Part 2: Simulation, J. Power Sources. 179 (2008) 785-792. doi:10.1016/j.jpowsour.2007.12.022.

[49] D.H. Jang, Electrolyte Effects on Spinel Dissolution and Cathodic Capacity Losses in 4 V LiLi[sub x]Mn[sub 2]O[sub 4] Rechargeable Cells, J. Electrochem. Soc. 144 (1997) 3342. doi:10.1149/1.1838016.

[50] A. Blyr, Self-Discharge of LiMn[sub 2]O[sub 4]/C Li-Ion Cells in Their Discharged State, J. Electrochem. Soc. 145 (1998) 194. doi:10.1149/1.1838235.

[51] G. Ning, B.N. Popov, Cycle Life Modeling of Lithium-Ion Batteries, J. Electrochem. Soc. 151 (2004) A1584. doi:10.1149/1.1787631.

[52] P. Verma, P. Maire, P. Novák, A review of the features and analyses of the solid electrolyte interphase in Li-ion batteries, Electrochim. Acta. 55 (2010) 6332-6341. doi:10.1016/j.electacta.2010.05.072.

[53] V. a. Agubra, J.W. Fergus, The formation and stability of the solid electrolyte interface on the graphite anode, J. Power Sources. 268 (2014) 153-162. doi:10.1016/j.jpowsour.2014.06.024.

[54] D. Aurbach, Review of selected electrode-solution interactions which determine the performance of Li and Li ion batteries, J. Power Sources. 89 (2000) 206-218. doi:10.1016/S0378-7753(00)00431-6.

[55] L. Liu, J. Park, X. Lin, A.M. Sastry, W. Lu, A thermal-electrochemical model that gives 
spatial-dependent growth of solid electrolyte interphase in a Li-ion battery, J. Power Sources. 268 (2014) 482-490. doi:10.1016/j.jpowsour.2014.06.050. 